\title{
LA JUSTICIA CRIMINAL EN AMÉRICA LATINA Y EL NARCOTRÁFICO: LA OBSERVACIÓN DE LOS DERECHOS HUMANOS EN LA BÚSQUEDA DE LA LEY Y EL ORDEN
}

\author{
Migdalia De Jesús Torres*
}

\section{INTRODUCCIÓN}

Todas las relaciones humanas están en una medida u otra atravesadas por la dimensión jurídica. Inclusive se podría decir que en su mayoría estas relaciones son "producto de construcciones histórico-sociales en cuya factura han figurado y figuran significativamente la normas jurídicas" (Rivera Ramos, 1992) '. Implica esto que en las relaciones entre la sociedad civil y el estado, entre el estado y los ciudadanos, y entre los ciudadanos mismos existe una dimensión jurídica. Esta dimensión jurídica abarca lo público y lo privado, y determina lo que debe ser incluido y excluido según los parámetros establecidos por los derechos. Son los derechos los que deben establecer los parámetros y no viceversa. Los derechos hay que entenderlos como parte constitutiva de la vida social, económica, y política. Son parte integral, reflejo y contenido, de la vida cotidiana por el mero hecho de nuestra categoría de seres humanos. Estos derechos existen aún cuando el individuo ignora su existencia y no los reclama como suyos o no los puede dar a valer. Los derechos sustentados en la ley legitimizan a las personas poseedoras de esos derechos ante los tribunales. Estas personas están legitimadas mientras exista la ley, y ésta no entre en conflicto con algún decreto protector de la seguridad nacional. Si el derecho no está identificado en una ley o éste entra en conflicto con un decreto operacional en particular, y si las circunstancias ameritan la observación de ese derecho para preservar la condición humana, éste existe. La condición humana exige un trato equitativo, respetuoso, igual, digno, y justo. En los casos donde la dimensión jurídica es apropiada como propiedad solamente de algunos y no de otros con la intención de violentar los derechos en nombre de la ley y el orden, las personas tienen el deber de reclamar como suyos esos derechos aún en ausencia de la ley protectora. Cuando se le da a esos derechos rango de propiedad privada de los foros (Naciones Unidas, tribunales, gobiernos y otros) responsables por vigilar su establecimiento, aplicación o implementación esto significa una apelación continua a ellos ya que para ellos no existen técnicamente esos derechos fuera de su visto bueno o reconocimiento.
La tricotomía de los derechos civiles, constitucionales y humanos, en los países de tradición democrática liberal con una economía capitalista, fragmenta a esos mismos derechos y tiene el potencial de situarlos en una posición enemiga entre sí. Lo mismo sucede al distinguir como derechos separados los derechos políticos, económicos y sociales sin integrarlos en alguna medida. Al negarle a esos derechos una dimensión multidimensional e integrada en efecto se está negando el acceso y defensa del derecho invocado dentro y fuera de la ley. Se convierte en objeto del derecho la persona. Está claro que cada uno de estos derechos tiene un contenido específico y diferenciado y que cubren un ámbito necesario, al segregarlos bajo la categoría de derecho civil, derecho constitucional, y derecho humano se socava en alguna medida la intención de proteger a la persona. ¿Acaso existe un derecho político que no tenga una dimensión social y económica, o un derecho económico que no tenga una dimensión social y política, o un derecho social que no tenga una dimensión política y económica? ¿No son todos estos derechos esencialmente constitucionales, civiles y humanos? El diferenciar o particularizar los derechos y ponerlos en el contexto que les corresponde, según el tipo de opresión o violación o protección, es necesario, pero hay que integrarlos para que así no se perpetúe la negación del mismo derecho.

\section{SEGURIDAD}

Se da este caso con relación a las medidas gubernamentales en persecución del crimen, los criminales, y el tráfico de drogas. En este esfuerzo entran en vigor entidades nacionales e internacionales con sus propósitos similares y diversos. Nuevas leyes, decretos y funciones gubernamentales son creadas. Ejemplo, la Ley Antiabuso de Drogas de 1986 ha creado un problema de política hegemónica al establecer sanciones, certificaciones, acuerdos de cooperación

Proyecto Puertorriqueño/Latinoamericano en Justicia Criminal John Jay College of Criminal Justice.

1. Ramos Rivera, E. (1992): Los Derechos Civiles: Retos del Presente $y$ del Porvenir. San Juan, Puerto Rico: Instituto Puertorriqueño de Derechos Civiles. 
y ayudas anuales de EEUU. El Gráfico I ${ }^{2}$ especifica el presupuesto internacional antidrogas de EEUU.

GRÁFICO I

\section{Presupuesto de EE.UU. para el control internacional de drogas, 1994-1996 (millones de dólares)}

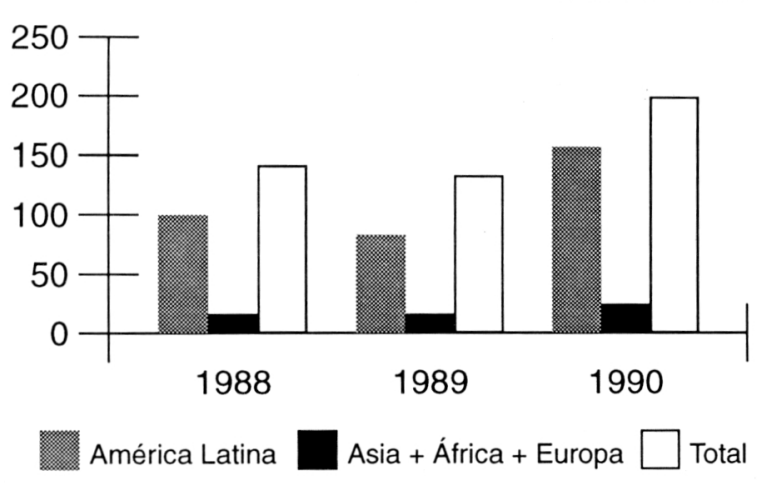

Fuente: Departamento de Estado de EE.UU. 1995, INCSR

Imponiendo "...su discurso prohibicionista y sus estrategias para el control antidrogas..." EEUU ha ayudado a "desestabilizar" la situación política aún más (Lessmann, 1997) ${ }^{3}$. Sus organismos como el Tactical Analysis Teams (militares y servicio secreto), Comando Sur de EEUU, Command Management Systems (sistemas de comunicación y vigilancia aérea), el Centro para el Conflicto de Baja Intensidad del Pentágono, DEA, paramilitares, y otras entidades necesarias para información de la inteligencia se han movilizado a través de América Latina para coordinar esfuerzos antidrogas.

Tulchin $(1997)^{4}$ explica que "...la respuesta latinoamericana nunca ha sido bastante fuerte como para establecer un control civil nacional o multilateral...." Si el problema del narcotráfico se define como un problema de seguridad nacional e internacional, las agendas las establecen cuerpos militares y especializados dejando fuera en gran medida a las instituciones civiles. "La lucha contra el narcotráfico se ha militarizado, y ha hecho conflictivo parte del debate sobre seguridad y defensa" (Tulchin, 1997) ${ }^{5}$. Rojas Aravena y Milet $(1997)^{6}$ sintetizan en el siguiente Gráfico II, los casos y la situación existente:

La preocupación con la soberanía y la posible intervención directa en territorio nacional bajo los acuerdos bilaterales antidrogas, cuyo propósito es la de preservar la seguridad nacional e internacional, lleva a algunos líderes de países ya intervenidos a declarar sus objeciones. Griffith (1997) indica que "...la soberanía de muchos países caribeños está sujeta a ser infringida por actores estatales y no estatales, debido a la droga" ?. En el Gráfico III vemos como la ayuda económica y militar de EEUU en Bolivia, Columbia y Perú durante el 1989-1994 no ayudó a resolver los problemas de gobernabilidad o derechos humanos ${ }^{8}$.

Afirma Griffith (1997) “...El Narcotráfico tiene operaciones múltiples... pues están involucradas... (producción, [procesamiento] consumo, abuso, tráfico [comercialización] y lavado de dinero)..." y la "...seguridad es multidimensional, tiene dimensiones militares, económicas, y políticas" "
GRÁFICO ॥

La situación que existe a nivel regional, se sintetiza en el siguiente cuadro:

\begin{tabular}{|c|c|c|}
\hline País & $\begin{array}{l}\text { Es el narcotráfico un } \\
\text { problema de seguri- } \\
\text { dad nacional }\end{array}$ & $\begin{array}{l}\text { Están las fuerzas armadas involu- } \\
\text { cradas en la lucha contra el } \\
\text { narcotráfico }\end{array}$ \\
\hline ARGENTINA & $\begin{array}{l}\text { Es un problema a la } \\
\text { seguridad }\end{array}$ & $\begin{array}{l}\text { Existe un debate en curso sobre } \\
\text { el rol de las fuerzas armadas en } \\
\text { este campo }\end{array}$ \\
\hline BOLIVIA & $\begin{array}{l}\text { Es un problema de } \\
\text { seguridad nacional }\end{array}$ & Sí, con ayuda de Estados Unidos \\
\hline BRASIL & $\begin{array}{l}\text { Es un problema de } \\
\text { seguridad nacional }\end{array}$ & $\begin{array}{l}\text { Las fuerzas armadas no están } \\
\text { consideradas en actividades } \\
\text { represivas, sin embargo en la } \\
\text { política de defensa se dice que } \\
\text { deben estar preparadas para res- } \\
\text { ponder a posibles amenazas }\end{array}$ \\
\hline CANADÁ & $\begin{array}{l}\text { Es un problema mul- } \\
\text { tilateral, que no debe } \\
\text { ser tratado sólo a } \\
\text { nivel nacional }\end{array}$ & $\begin{array}{l}\text { Estarían preparadas, pero no es } \\
\text { su prioridad. Sí lo es la partici- } \\
\text { pación en las operaciones de paz } \\
\text { de la ONU }\end{array}$ \\
\hline CARIBE & $\begin{array}{l}\text { Es un problema de } \\
\text { seguridad nacional }\end{array}$ & $\begin{array}{l}\text { Es visto como una prioridad por } \\
\text { las fuerzas armadas, pero éstas no } \\
\text { consideran que sean el único } \\
\text { organismo que debe combatirlo }\end{array}$ \\
\hline CHILE & $\begin{array}{l}\text { Es un fenómeno } \\
\text { delictual que abarca } \\
\text { múltiples ámbitos, } \\
\text { como la economía, la } \\
\text { salud y la educación }\end{array}$ & No, sólo los organismos policiales \\
\hline COSTA RICA & $\begin{array}{l}\text { Es un problema de } \\
\text { seguridad nacional }\end{array}$ & $\begin{array}{l}\text { No, esa función la desarrollan las } \\
\text { fuerzas policiales. No existen } \\
\text { fuerzas armadas }\end{array}$ \\
\hline CUBA & $\begin{array}{l}\text { Es un problema eco- } \\
\text { nómico-social }\end{array}$ & $\begin{array}{l}\text { No, sólo actuarían si fuera } \\
\text { necesario }\end{array}$ \\
\hline ESTADOS UNIDOS & $\begin{array}{l}\text { El narcotráfico es un } \\
\text { problema para la } \\
\text { seguridad nacional y } \\
\text { regional }\end{array}$ & $\begin{array}{l}\text { La estrategia de lucha debe invo- } \\
\text { lucrar a las fuerzas armadas y } \\
\text { también plantearse como una } \\
\text { acción coordinada de éstas a } \\
\text { nivel hemisférico }\end{array}$ \\
\hline MÉXICO & $\begin{array}{l}\text { Es un problema de } \\
\text { seguridad nacional }\end{array}$ & $\begin{array}{l}\text { Sí, por la imposibilidad de los } \\
\text { organismos policiales de } \\
\text { combatirlo }\end{array}$ \\
\hline PERÚ & $\begin{array}{l}\text { Es un problema de } \\
\text { seguridad nacional }\end{array}$ & Sí, intervienen en su lucha \\
\hline VENEZUELA & $\begin{array}{l}\text { Es un problema de } \\
\text { seguridad nacional }\end{array}$ & $\begin{array}{l}\text { Las fuerzas armadas participan } \\
\text { en la represión de este delito }\end{array}$ \\
\hline
\end{tabular}

2. Cimadamore, A.D. (1997): "La política antidrogas de Estados Unidos: Condicionantes internos y efectos intra-hemisféricos" en Drogas el conflicto de fin de siglo. Caracas, Venezuela: Cuadernos de Nueva Sociedad.

3. Lessmann, R. (1997, septiembre). El narcotráfico y las relaciones interamericanas. Caracas, Venezuela: Cuadernos de Nueva Sociedad.

4. Tulchin, J. (1997). "El narcotráfico y la seguridad hemisférica" en Paz V. Milet (comp.): Narcotráfico y seguridad en América Latina y el Caribe. Santiago, Chile: FLACSO.

5. Ibid., p. 9.

6. Rojas Aravena, F. y Milet, P. V. , Introducción, p. 7.

7. Griffith, I. L. (1997). El narcotráfico como una cuestión de seguridad en el Caribe en PazV. Milet (comp.) Narcotráfico y seguridad en América Latina y el Caribe. Santiago, Chile:FLACSO.

8. Youngers, C. (1997). El pantanal andino: Estados Unidos y el control de drogas en los Andes. Caracas, Venezuela: Cuardernos Nueva Sociedad, p. 76.

9. Griffith, I. L. p. 24. 
GRÁFICO III

\begin{tabular}{|c|c|c|c|c|}
\hline \multicolumn{5}{|c|}{$\begin{array}{l}\text { Ayuda económica y militar para la aplicación } \\
\text { de Ley Antidrogas a Bolivia, Colombia y Perú, 1989-1994 } \\
\text { (En miles de dólares de EE.UU.) }\end{array}$} \\
\hline & Economía & Policía & Militar & Total \\
\hline Bolivia & 580.991 & 125.822 & 144.401 & 851.214 \\
\hline Colombia & 119.366 & 167.718 & 342.323 & 628.676 \\
\hline Perú & 323.788 & 102.790 & 49.648 & 476.226 \\
\hline Totales & 1.024 .145 & 396.330 & 536.372 & 1.956 .116 \\
\hline
\end{tabular}

Alcides Costa (1997) describe que "la agenda de seguridad tiene que considerar los procesos regionales como la reforma del Estado, la apertura de las economías, la revitalización del regionalismo económico y el deterioro de las condiciones sociales" ${ }^{10}$.

\section{DERECHOS HUMANOS}

En las comunidades con desventajas donde impera la pobreza, la marginalización, y el desosiego se da la actividad más intensa con relación a la intervención antidrogas. En estas comunidades son violados todos por igual los derechos sociales, políticos y económicos aunque sean estipulados en convenios, códigos, constituciones, cartas, y decretos. Vargas Meza (1997) identifica las siguientes violaciones a los derechos humanos en Buenos Aires de Miraflores en Colombia:
1. "Incendio de viviendas de los campesinos con todos sus haberes sin que se les permitiese sacar algo de las casas.

2. Robos de joyas, dineros y enseres por parte de quienes adelantan los operativos.

3. Órdenes de desalojo de zona sin derecho a retornar por los bienes o las fincas.

4. Acusaciones de ser narcoguerrilleros y por tanto objeto de medidas inconsultas y violatorias de los procedimientos judiciales establecidos.

5. Riguroso control a la circulación de alimentos o medicamentos para la región.

6. Incautaciones de radiotransmisores de las comunidades, prejuzgadas como auxiliadores de la guerrilla" ".

En Perú, se “...sancionó una Ley de Amnistía (1995) que limpiaba los expedientes de los agentes gubernamentales...” y a la misma vez en tribunales militares secretos "...son cientos y cientos los encarcelamientos de cuidadanos inocentes que sufren condenas de veinte años o cadena perpetua" (Youngers, 1997) ${ }^{12}$.

Los organismos internacionales preocupados por vigilar la implementación de los diferentes convenios, cartas, y decretos de los derechos humanos encuentran poco apoyo al llegar la hora de fiscalizar a los gobiernos y los militares en sus prácticas anticrimen. Bajo la bandera de ley y orden muchos gobiernos y sus funcionarios corren desbocados a implementar decretos con la aprobación de las fuerzas especiales y militares. Muchos de estos decretos se convierten en leyes cuya función es la de minar otras leyes existentes protectoras de los derechos políticos, sociales, económicos, y personales. Se ignoran las constituciones, y los otros instrumentos protectores del ciudadano ante el poder arrollador del gobierno y sus diferentes ramas. En las redadas policiales y militares, con el propósito de arrestar ciudadanos bajo la sospecha de que están involucrados, o que presuntamente tienen información o son conocedores de los diferentes puntos de drogas o de acciones terroristas, a menudo se les violan todos los derechos estipulados por la ley y aquellos derechos que emanan por la condición esencial de que son seres humanos. Lessmann (1997) detalla las violaciones en Bolivia:

1. "la instalación de tribunales especiales;

2. la incorporación de fuerzas del ejército al área de investigaciones civiles;

3. la ejecución de determinados proyectos legislativos;

4. la realización de pruebas secretas e ilegales con herbicidas contra las plantaciones de coca;

5. el despido de determinados funcionarios;

6. la deportación de presuntos involucrados en delitos de tráfico de drogas;

7. intervención militar temporal por iniciativa de EEUU o ejecutada directamente por este país" ${ }^{13}$.

Entidades militares y policiales sin entrenamiento adecuado en el manejo de los derechos del ciudadano y en la observación absoluta de la ley, optan por las directrices operacionales en el cumplimiento de sus funciones. Son justificadas todas las violaciones, atropellos, y encubrimientos en nombre de la seguridad nacional, la ley y el orden. Sin embargo rara vez se les hacen redadas a las instalaciones de los de más alto rango social, político, o económico. El trato desigual entre las comunidades menos afortunadas y las de clase media o alta es obvio cuando se brega con el crimen a menos que también no haya una motivación política partidista o ideológica envuelta. A través de la consigna de acabar con el terrorismo, el tráfico de drogas, el uso de drogas, el crimen organizado, o los diferentes crímenes asociados con la pugna entre bandos en el tráfico de drogas, también se enmascara a menudo una lucha por el poder institucional de gobierno. Estas luchas por el poder entre los diferentes partidos, poderes económicos, y entidades internacionales interesados en el desarrollo de una ideología partidista aceptable hacia ellos genera campañas anti-crimen para justificar sus avanzadas. Lissmann (1997) avisa que "la posición hegemónica de EEUU se fortaleció indirectamente con el debilitamiento de la posición de esos países..." ${ }^{14}$. Analiza Lissmann (1997) que “...la militarización del combate contra el narcotráfico... modifica la frágil relación entre los sectores civiles de la sociedad y el ejército y pone en peligro el proceso democrático" ${ }^{15}$.

10. Costa Vaz, A. (1997). Narcotráfico y fuerzas armadas en América Latina en Paz V. Milet (comp.) Narcotráfico y seguridad en América Latina y el Caribe. Santiago, Chile: FLACSO.

11. Vargas Mesa, R. (1997). Colombia y el área andina. Caracas, Venezuela: Cuardernos Nueva Sociedad.

12. Youngers, C. p. 77.

13. Lessmann, R. p. 55

14. Ibid., p.54

15. Ibid., 55. 


\section{LAS INSTITUCIONES Y EL DERECHO}

Generalmente no sólo sufren las personas el asedio sino también las instituciones más vulnerables en la sociedad. Estas instituciones identificadas como responsables de preservar, vigilar, y promover los derechos son las que representan el segundo frente ante esas entidades gubernamentales y otras empeñadas en la campaña de la ley y el orden ante todo. El primer frente son las personas afectadas por las violaciones a sus derechos y las que, al no querer seguir siendo objetos, pasan a reclamar los derechos como suyos, independientemente del gobierno y sus dependencias o inclusive la ley. Son estas personas y las instituciones del segundo frente las que establecen una frontera en beneficio de la sociedad si logran a través de medidas legales defender sus derechos. En caso de que estas instituciones no puedan sostener el peso de las presiones gubernamentales, las de la sociedad reclamando acción en contra del crimen, y las necesidades de los afectados por las violaciones, entonces impera la ley y el orden según sea interpretado por las entidades envueltas en un momento dado. ¿Qué es lo que significa la ley y el orden, la ciudadanía y los intereses económicos para las autoridades gubernamentales? Para el gobierno y los poderes económicos significa un estado político-social con promesa de estabilidad y crecimiento en donde las inversiones no incurran en peligro de pérdidas, las regulaciones sean flexibles en favor de sus intereses, y los derechos estén medidos según el mercado económico. La democracia por ende es limitada por ellos a una definición que incluye principalmente el derecho a ir a las urnas y acceso al mercado o a las tiendas para ir de compras.

La ciudadanía entiende que necesita protección en contra del crimen y opta por sacrificar ciertos derechos en momentos críticos para estabilizar social, política y económicamente la sociedad. Usualmente son las clases de mayor poder social y económico las que llevan la voz cantante en el apoyo de la ley y el orden por que se creen las más vulnerables al crimen. Sin embargo, son los menos social y económicamente afortunados los que sufren los más recios ataques del crimen y también los castigos impuestos por las entidades encargadas de la ley y el orden. Esta misma ciudadanía que reclama ley y orden no espera excesos en el cumplimiento de las funciones policiales o del gobierno y sus dependencias cuando se trata de ciudadanos ajenos al crimen y la criminalidad. Los más conservadores aceptan que la ley y el orden deben regir aún a costa de los derechos de los llamados criminales y de los que los apoyan en alguna medida o sea por simpatía. Algunos ciudadanos comunes y corrientes están convencidos de que no se les puede atar las manos a las autoridades para que así puedan desempeñar sus funciones. $\mathrm{Al}$ abrirle la puerta a posibles abusos de autoridad, brutalidad policial o militar, y corrupción de los derechos, la ciudadanía en general corre el riesgo de perder sus más preciados valores humanos. Es en la coyuntura entre los derechos y su defensa o la ley y el orden donde la democracia se pone a prueba.

En varios países de América Latina la ley y orden o la mano dura contra el crimen sirven como promesa de campañas políticas ${ }^{16}$. La implementación de esta promesa de campaña se traduce en legislación que apoya arrestos bajo nuevas categorías de delitos, medidas operacionales de la policía o la guardia nacional cuestionables, en las penas altas de reclusión por la comisión de delitos, la reducción de medidas de rehabilitación, y la limitación de los derechos del confinado (Nevares-Muniz,1996) ${ }^{17}$. En Puerto Rico, con una alta taza de criminalidad relacionada con las drogas, enmiendas al Código Penal fueron efectuadas desde el 1993 al 1995. Estas enmiendas responden en contenido a los intereses del gobierno de EEUU y no a la solución real de los problemas o las necesidades de la ciudadanía ${ }^{18}$. En la capital federal norteamericana, la alcaldesa Sharon Pratt Kelly, "hizo la petición de desplegar a la Guardia Nacional en la ciudad para combatir el crimen organizado" ${ }^{19}$ una medida que ya ha sido implementada en Puerto Rico al dirigirse los esfuerzos anticrimen a los residenciales.

Columbia aprobó una reforma del Código de Procedimiento Penal para abrir las puertas a una entrega masiva de narcotraficantes y grupos de autodefensa en su iniciativa por estabilizar la política, tomar control de la opinión pública, y generar una mejor imagen del país ante el mundo con relación al narcotráfico. El Código ofrece opciones "de libertad provisional a aquellas personas que confiesen sus delitos y contribuyan a prevenirlo, a identificar a otros partícipes o a desarticular total o parcialmente grupos criminales" ${ }^{20}$. Estas opciones no están accesibles a todos los ciudadanos que hayan sido arrestados por estar vinculados al narcotráfico. Bolivia, Perú, Ecuador, Venezuela entre otros han emprendido similares ofensivas en nombre de combatir el crimen organizado, la corrupción, el lavado de dinero, el terrorismo, y las olas de crímenes ${ }^{21}$.

\section{CONCLUSIÓN}

La justicia criminal tiene que ser justa y observar los derechos aún por encima de la ley y el orden. El debate sobre el impacto que tienen las nuevas reformas a los códigos penales, administrativos, y de procedimiento con relación a los derechos tendrá que tomar lugar en foros nacionales al igual que internacionales. Los estudios de impacto son necesarios pero no se les da vigencia, pues implican posiblemente romper con las frágiles alianzas políticas que llevaron a las reformas en el primer lugar. Un estudio de impacto requiere un instrumento que mida las diferentes vertientes del problema y, al mismo tiempo, que sintetice los resultados. Es una especie de monitor, una vez se hagan las reformas que respondan a las necesidades de la sociedad, para

16. Latin American News Update, Monthly Foreign Press Digest (Chicago, Ill.). Es una publicación dedicada mensualmente a resumir los artículos en los periódicos más importantes de América Latina con relación a la política, el crimen y medidas gubernamentales.

17. Nevares-Muniz, D. (1996). El Crimen en Puerto Rico: Tapando el Cielo con la Mano (Hato Rey, Puerto Rico: Instituto para el Desarrollo del Derecho, Inc.).

18. Ibid., Leyes Num. 57, 83, 33, 117, 2,23, 5,7, y 158, p. 162.

19. Narcotráfico al Día 42 (1994). Comisión Andina de Juristas.

20. Narcotráfico al Día 42 (1994). Comisión Andina de Juristas.

21. Comisión Andina de Juristas, 1994. Es un recurso en la información que dispensa con relación a las medidas legislativas y preocupaciones de índole internacional. 
vigilar si esas reformas cumplen con los criterios establecidos por los derechos.

\section{BIBLIOGRAFÍA}

Cimadamore, A.D. (1997): “La política antidrogas de Estados Unidos: Condicionantes internos y efectos intrahemisféricos" en Drogas el conflicto de fin de siglo. Caracas, Venezuela: Cuadernos de Nueva Sociedad.

Costa VAZ, A. (1997): "Narcotráfico y fuerzas armadas en América Latina” en Paz V. Milet (comp.) Narcotráfico y seguridad en América Latina y el Caribe. Santiago, Chile: FLACSO.

GRIFFITH, I. L. (1997): "El narcotráfico como una cuestión de seguridad en el Caribe en Paz". Milet (comp.) Narcotráfico y seguridad en América Latina y el Caribe. Santiago, Chile: FLACSO.
LESSMANN, R. (1997): El narcotráfico y las relaciones interamericanas. Caracas, Venezuela: Cuadernos de Nueva Sociedad.

Nevares-Muniz, D. (1996): El Crimen en Puerto Rico: Tapando el Cielo con la Mano (Hato Rey, Puerto Rico: Instituto para el Desarrollo del Derecho, Inc.).

Ramos Rivera, E. (1992): Los Derechos Civiles: Retos del Presente y del Porvenir. San Juan, Puerto Rico: Instituto Puertorriqueño de Derechos Civiles.

Tulchin, J. (1997): “El narcotráfico y la seguridad hemisférica” en Paz V. Milet (comp.): Narcotráfico y seguridad en América Latina y el Caribe. Santiago, Chile: FLACSO.

Vargas Mesa, R. (1997): Colombia y el área andina. Caracas, Venezuela: Cuardernos Nueva Sociedad.

YOUNGERS, C. (1997): El pantanal andino: Estados Unidos y el control de drogas en los Andes. Caracas, Venezuela: Cuardernos Nueva Sociedad.

Narcotráfico al Día 42 (1994): Comisión Andina de Juristas.

\section{RESUMEN}

Los derechos son constitutivos de la vida social, económica y política, y deben ser ellos los que deben establecer los parámetros de lo público y lo privado, y la dimensión jurídica que de dicha separación se deriva. Bajo esta premisa el artículo aborda la cuestión del narcotráfico y la justicia criminal en América Latina. Es un hecho que la búsqueda de la ley y el orden, la seguridad lleva, en muchas ocasiones, a la inobservancia de los derechos humanos, con lo que entran en conflicto las actuaciones policiciales y gubernamentales con los derechos individuales, generalmente de los más desprotegidos social y económicamente. Otro aspecto importante es la cuestión de cómo la soberanía de los países latinoamericanos se ve afectada por la puesta en práctica de leyes antidroga, auspiciadas por EE.UU. con su política hegemónica, que establece sanciones, acuerdos de colaboración y ayudas anuales en función de la lucha internacional en contra del narcotráfico que este país defiende en América Latina.

Palabras clave: Derechos Humanos, Constitucionales y Civiles; Ley y Orden; Seguridad Nacional; Narcotráfico; Justicia; Soberanía; Legislación; Leyes Antidroga.

\section{ABSTRACT}

Laws are the constitutive framework of social, political and economic life. As such, they should legally establish the parameters between the public and private sectors. With this premise, the article broaches upon the subject of narcotic trafficking and criminal justice in Latin America. The search for security, law and order may often lead to the neglect of human rights; a situation in which police and government actions enter into conflict with the rights of individuals who are generally the most socially and economically unprotected. Another important aspect relates to how the sovereignty of Latin American countries has been affected by the implementation of anti-drug laws by the United States a hegemonic policy that has established sanctions, treaties and annual support-incentives to wage an international fight against drug trafficking in Latin America.

Key words: Human Rights; Constitutional and Civil Law; Law and Order; National Security; Narcotics and Drug Trafficking; Justice; Sovereignty; Legislation; Anti-drug Laws. 


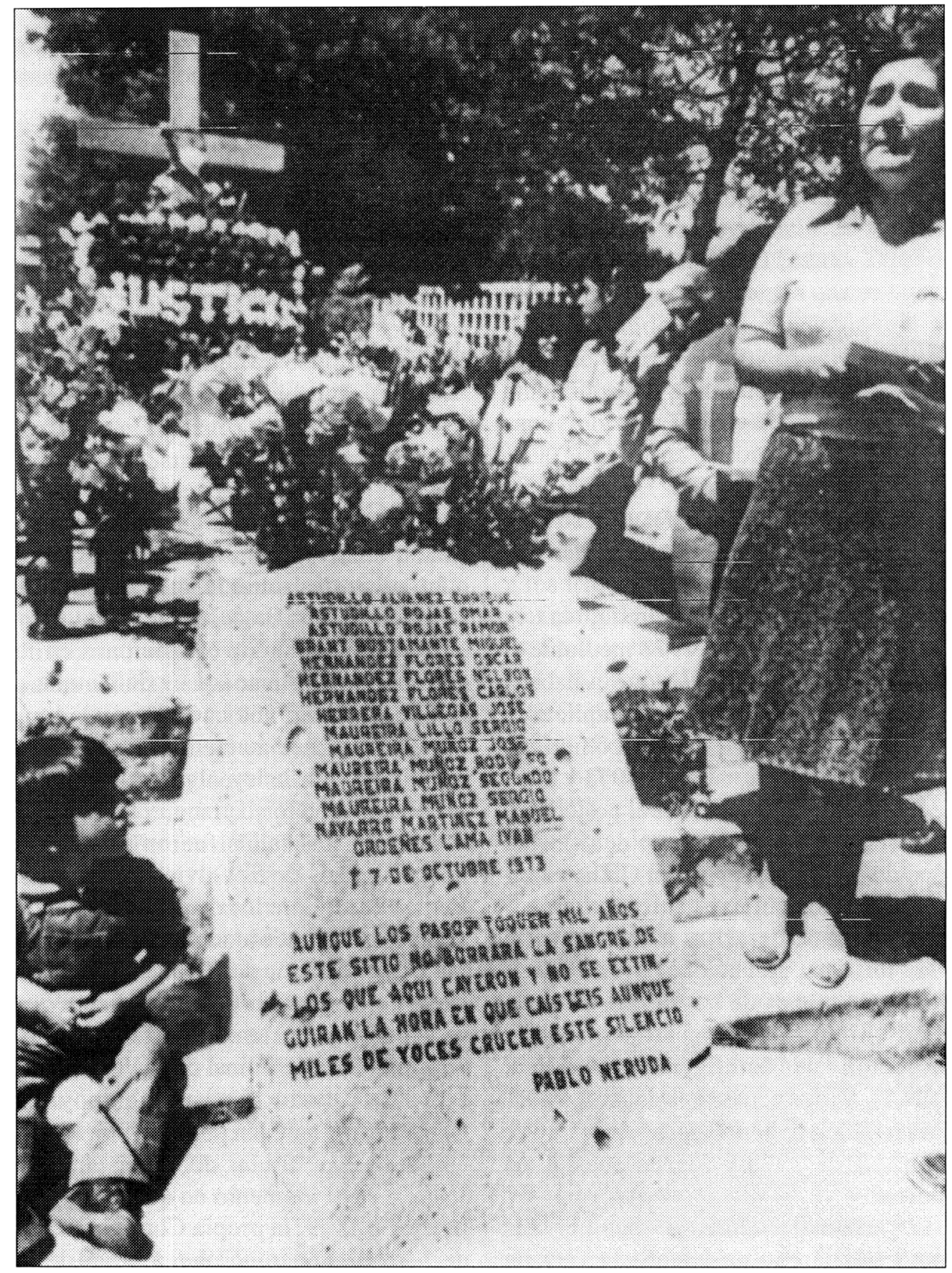

Memorial por 15 presos "desaparecidos" cuyos restos fueron encontrados en Lonquén, Chile (@ Associated Press) (Gentileza de "Amnistía Internacional”) 